\title{
"Nossa mata, nosso rio, nosso mangue": a escola em narrativas de professores(as) indígenas
}

\author{
Karla Cunha Pádua
}

\section{Resumo}

O texto discute a apropriação da escola por professores(as) indígenas, da etnia Pataxó, que cursaram a primeira turma do curso de Formação Intercultural de Educadores Indígenas (FIEI), oferecido pela Universidade Federal de Minas Gerais (UFMG). Tal processo de apropriação acontece no diálogo entre as formas próprias de relação com o conhecimento e as redes de relações e interlocuções construídas nos cursos de formação de educadores, que possibilita a produção de novas experiências e significações. Nesse diálogo, concepções próprias de conhecimento como projeto e como pesquisa, transformam a escola em centro da vida comunitária, lugar de exercício de pesquisa permanente e ligada à prática social, que os ajuda a repensar a sua relação com o mundo e a produzir seus projetos de futuro.

Palavras-Chave: escola indígena; formação intercultural; professores(as) Pataxó. 


\section{"Our forest, our river, our mangue": the school through indigenous teachers narratives}

\section{Summary}

This article discusses the appropriation of school by indigenous teachers from Pataxó ethnic group who took part in the first Intercultural Formation Course of Indigenous Educators carried out at Federal University of Minas Gerais. Such a process was achieved through a dialogue between the teachers' own forms of relationship with knowledge and the nets of relationships and interlocutions built in this context, which allowed the production of new experiences and meanings. Within such a dialogue, teachers own conceptions of knowledge such as project and research have turned the school into a center of community life, a place in which research is seen as permanent and linked to social practice, which allows them rethink their relationship with the world and design their future projects.

Keywords: Indigenous School, Intercultural Formation, Pataxó Teachers.

A escola, como nós falamos, ela hoje é nossa mata, nosso rio, nosso mangue. A escola ela é hoje tudo pra nós aqui.

[A] escola não é uma coisa de fora não, é escola nossa. Porque, muitas vezes, as pessoas falam assim: 'a escola é uma coisa de fora', realmente, é uma coisa que foi. Aqui dentro, pra nós, ela não é uma coisa de fora não, porque a gente tá tentando trabalhar o que é nosso. Então, só no papel lá fora que é do branco.

Kanatyo 
Essas falas da epígrafe nos ajudam a entender a centralidade da escola hoje na vida da aldeia Muã Mimatxi, localizada em Itapecerica-MG' ${ }^{2}$. Ao dizer que a escola "é nossa mata, nosso rio, nosso mangue", Kanatyo, cacique e professor nessa aldeia Pataxó, apresenta metaforicamente as expectativas dessa comunidade de que a escola seja, ao mesmo tempo, fonte de memória e de autossustentação, lugar privilegiado para gerar frutos que vão garantir a sua reprodução social e o futuro das novas gerações. É nesse sentido que completa: "a escola é hoje tudo pra nós aqui".

É importante compreender essas falas no contexto do Brasil contemporâneo, de afirmação étnica de vários povos indígenas, no qual a valorização da "cultura" adquiriu uma dimensão importante na vida da maioria desses povos. Esse grupo Pataxó, já tendo conquistado reconhecimento étnico, um território para viver, uma escola e um Posto de Saúde na aldeia, tem investido agora no processo de revitalização da "cultura" e de seus saberes tradicionais. E a escola tem sido um lugar onde podem semear ideias que, na medida em que vão sendo trabalhadas e desenvolvidas, ajudam a produzir novos sujeitos sociais e novos projetos de vida para a coletividade.

As concepções expressas por Kanatyo reforçam as abordagens que enfatizam o processo de ressignificação local de instituições, inicialmente "estrangeiras", por meio da sua incorporação e recontextualização aos códigos culturais locais (SAHLINS, 1997 a e b; TASSINARI, 2001; LASMAR, 2009). Isso explicaria a grande diversidade de modos de relação com a escola por parte de vários povos indígenas, cujas respostas locais à lógica dessa instituição "ocidental" necessitam ser investigadas. Nessa perspectiva, é possível compreender a fala de Kanatyo de que hoje a escola é parte de seu universo e não uma instituição alheia, mas um espaço ressignificado pelos índios da aldeia Muã Mimatxi.

Entretanto, segundo Tassinari (2001), a escola indígena é também um

2 Os dados aqui apresentados foram coletados em maio de 2012, no contexto da pesquisa Repercussões da Formação Intercultural na Vida de Professores(as) Indígenas. Resultam de entrevistas narrativas realizadas com professores(as) dessa aldeia e de observação participante de atividades escolares. A maioria dos(as) entrevistados(as) participou da primeira turma do curso de Formação Intercultural de Educadores Indígenas (FIEI), curso especial de graduação oferecido pela UFMG. Uma parte da análise desse material empírico se desenvolveu durante o estágio pós-doutoral em Antropologia, financiado pela CAPES, no Instituto de Ciências Sociais da Universidade de Lisboa, com a colaboração de Susana de Matos Viegas. 
espaço de fronteira e, enquanto tal, como o xamã, introduz o desafio de se relacionar também com forças poderosas, perigosas e com um potencial destrutivo. Mas, na perspectiva dos(as) professores(as) Pataxó da aldeia Muã Mimatxi, a escola parece ter sido apropriada como um espaço intercultural, tal como para os Kaxinawá, estudados por Weber (2006). Mas aqui o intercultural adquire um sentido de ampliar as oportunidades de trocar conhecimentos e relações entre si e com os assessores "brancos" para produzir novas experiências e significações.

O projeto que os(as) professores(as) da aldeia Muã Mimatxi tem hoje para a escola foi construído, desde o início, em colaboração com os professores formadores, a maioria ligados à UFMG, com os quais tiveram contato desde a primeira turma do Magistério Indígena. O processo de implantação da educação diferenciada, um direito conquistado na Constituição de 1988, implicou o envolvimento de diferentes atores sociais na implantação das escolas indígenas, conduzidas por professores índios. O funcionamento da escola em terras indígenas exigia a formação desses professores. Em Minas Gerais, foi oferecido, em 1995, o primeiro curso de Magistério Indígena, no Programa de Implantação das Escolas Indígenas de Minas Gerais (PIEI-MG), da Secretaria de Estado da Educação (SEE-MG), em parceria com a UFMG e outras instituições (PÁDUA, 2009).

Conforme ressaltou Rezende (2009), a formação de professores indígenas no PIEI tinha como proposta a criação de escolas culturalmente sensíveis à diversidade das comunidades indígenas e das diferentes tradições étnicas. Visando garantir a influência dos povos indígenas sobre as práticas educativas a serem desenvolvidas nas escolas, esse Programa propunha uma formação voltada para a pesquisa e a produção de materiais didáticos, valorizando a autonomia e as identidades culturais de cada povo. Segundo essa autora, a experiência metodológica do PIEI ajudou a consolidar um paradigma educacional inclusivo, com base na ideia de formar professores como pesquisadores de sua própria cultura, que norteou a proposta pedagógica do curso de Formação Intercultural de Professores Indígenas (FIEI).

O FIEI, em sua proposta pedagógica e curricular, sugeria conectar 
a formação com as necessidades e o ritmo da vida das comunidades indígenas, estimulando os(as) professores(as) indígenas a se tornarem pesquisadores(as) de sua própria cultura. Entre os principais aspectos do curso, podemos destacar o compromisso da formação com o desenvolvimento da escola indígena e o desenho currícular flexível como contrapartida a uma estrutura rígida e fragmentada de aprendizagem (REZENDE, 2009).

A elaboração dessa proposta diferenciada de formação de professores indígenas em Minas Gerais nasceu de diálogos mais amplos dos professores da $\mathrm{UFMG}^{3}$ com outras experiências de educação indígena que se desenvolviam no país, especificamente a Comissão Pró-Índio do Acre (CPI/AC). Da experiência de autoria, desenhada na CPI/AC, que propõe envolver os alunos em um processo coletivo de criação e produção de textos, nasceu uma concepção de ensino como experiência e como percurso, que coloca a pesquisa como eixo transversal ao currículo, que marcou a orientação metodológica do FIEI (PÁDUA, 2009).

Para compreendermos o momento atual no processo de construção da escola diferenciada na aldeia Muã Mimatxi, é importante discutir suas redes de relações, a partir das quais ocorre o que Rappaport e Pacho (2005, p. 40) chamam de "apropriação crítica de sistemas externos de conhecimento, emaranhados por um pensamento próprio".

\section{Conhecimentos e significados de escola colhidos (ou pescados) em contextos interculturais}

O fato de a formação inicial de professores indígenas em Minas Gerais ter surgido do diálogo mais amplo das equipes pedagógicas da SEEMG com professores universitários e desses, por sua vez, com modelos alternativos e inovadores de educação indígena, com certeza influenciou uma orientação diferente e mais positiva de formação. Grupioni (2013) lembra que muito antes de existir uma política pública de formação de professores indígenas havia, durante as décadas de 80 e 90, experiências de discussão e proposição de novas práticas, que ocorriam fora do âmbito

3 Especialmente da professora Márcia Spyer, da Faculdade de Educação da UFMG, que coordenou a primeira turma de Magistério Indígena do PIEI, em 1995. 
do Estado, como é o caso da CPI/ AC.

Weber (2006) recupera a história da Comissão Pró-Índio do Acre, fundada em 1979, por Terri Aquino, com o desenvolvimento de projetos com os Kaxinawá, que ligavam desenvolvimento da comunidade e educação indígena. As primeiras experiências educacionais desenvolvidas por essa ONG indigenista, inspiradas nas ideias de Educação como Prática da Liberdade, de Paulo Freire, visavam formar índios para gerenciar cooperativas de seringueiros, oferecendo alfabetização e o domínio de operações básicas de matemática.

Segundo essa autora, o setor de educação da CPI/ AC organizou, em 1983, um primeiro curso para "monitores indígenas", coordenado por Nietta Monte; em 1985, no segundo curso, já se oferecia aulas de língua indígena, ministradas pela linguista Ruth Monserrat. Entretanto, para enfrentar as dificuldades de aceitação por parte dos índios, dessa perspectiva de estudar e escrever suas línguas maternas, surgiu o projeto Uma experiência de autoria, que inspirou os professores da UFMG na elaboração das propostas de formação de professores indígenas em Minas Gerais.

Tal projeto visava, segundo Weber (2006, p. 105-6), o fortalecimento das identidades étnicas dos grupos participantes, incentivando a transmissão das manifestações da cultura tradicional, tais como cantos, danças, mitos e plantas medicinais; a produção de material didático adaptado à realidade indígena, como, por exemplo, as cartilhas de alfabeltização escritas em línguas indígenas e as "viagens de assessoria" às escolas indígenas.

Em início dos anos 90, a organização não governamental Comissão Pró-Índio do Acre (CPI/AC) já desfrutava de considerável prestígio no cenário indígena e indigenista acreano. A entidade fora a responsável pela demarcação de várias terras indígenas, além de ter desenvolvido projetos pioneiros nas áreas de desenvolvimento comunitário, educação e saúde junto às populações indígenas desse estado. (WEBER, 2006, p. 104)

Grupioni (2013) lembra que foi em experiências como essa que nasceram programas que propunham a escola como espaço de valorização e sistematização de conhecimentos e saberes tradicionais e de reforço do uso da língua materna e não apenas como um lugar de acesso aos conhecimentos dos não índios. Tais experiências se 
tornaram referências para a formulação de políticas públicas de formação professores indígenas e para práticas inovadoras que se multiplicaram no país; foi a partir delas que surgiu a proposta de formar índios como professores e, ao mesmo tempo, agentes comunitários.

Entretanto, segundo Grupioni (2013), havia um grande diferencial nessas experiências, já que contavam com assessores (indigenistas e pesquisadores universitários), oriundos de várias áreas de conhecimento, que tinham vínculos com as comunidades e que estavam comprometidos com ações de intervenção e com o desenvolvimento de projetos comunitários locais, não apenas relacionados à educação. Experiências pioneiras de docência, orientação de pesquisas e preparação de materiais didáticos, alternativas às práticas integradoras do órgão indigenista, conduzidas por organizações não governamentais, surgiram nesse contexto com o objetivo de qualificar os membros das comunidades indígenas para uma relação menos desigual e exploratória com segmentos da sociedade envolvente.

Quando na década de 90 a formação de professores indígenas se tornou uma política de Estado, com as Secretarias de Estado da Educação incubidas da formação inicial e continuada de professores indígenas, de acordo com Grupioni (2013, p. 73),

uma empobrecida grade curricular se impôs, cada vez menos ancorada nas especificidades dos grupos envolvidos, resultando numa perda de densidade antropológica e linguística, em prol do repasse de conteúdos e competências exclusivas à função docente nas primeiras séries do Ensino Fundamental.

Esse autor critica a não priorização da formação para a pesquisa nas propostas originadas nos sistemas de ensino, aspecto que considera fundamental para subsidiar a produção de materiais didáticos e a elaboração dos projetos político-pedagógicos para as escolas indígenas. Entretanto, como vimos, não foi esse o caso da formação recebida pelos(as) professores(as) indígenas da aldeia Muã Mimatxi, para quem as pesquisas que realizaram nos Percursos Acadêmicos do FIEI se destacaram em suas narrativas como uma das aprendizagens mais significativas ${ }^{4}$.

4 Dada a importância deste tema na pesquisa, será explorado no contexto de outro artigo. 
Esse elemento curricular permitia a cada estudante traçar um caminho específico dentro do curso, de acordo com seus interesses e com as demandas de suas comunidades, e se estruturava a partir de uma dupla articulação: com uma "área de conhecimento" e com os "projetos sociais" de sua comunidade.

Esses programas de formação implementados em Minas Gerais desde o seu início dialogaram, por meio da assessoria de professores(as) da UFMG, com aquelas experiências pioneiras, mencionadas anteriormente. A interloculação com essas redes de pesquisadores parece ter influenciado positivamente a formação dos(as) professores(as) da aldeia Muã Mimatxi, embora não possamos generalizar isso para o conjunto de professores indígenas que participaram desses programas de formação, oriundos de diversas etnias e contextos socioculturais, sendo importante analisar caso a caso. Como ressaltou Grupioni (2013, p. 76), os cenários de complexa interação em que estão inseridos os(as) professores(as) indígenas produzem muitos discursos (e também muitas práticas), "que se adaptame são moldados de modo próprio a cada contexto particular de interlocução".

No caso de programas de formação que priorizam a pesquisa, é importante também investigar os profissionais que orientam as pesquisas desenvolvidas pelos(as) professores(as) indígenas, o conhecimento e interação que possuem com os diferentes universos étnicos e socioculturais e o domínio da bibliografia a respeito dos grupos com os quais trabalham, como destacou Grupioni (2013). Essas questões, segundo esse autor, influenciam os resultados, podendo dar origem a produções com pouca densidade ou, ao contrário, que revelem mais do que conteúdos, mas os modos de pensar desses grupos. A respeito desse aspecto, pensamos que a formação do pesquisador no contexto da educação indígena é um tema complexo, que demanda um acompanhamento contínuo, não podendo se encerrar com a conclusão dos cursos de formação inicial, exigindo um processo continuado e prolongado de formação e/ ou de assessoria nas aldeias ${ }^{5}$.

A escola indígena diferenciada vem sendo construída nesse processo

5 Podemos mencionar, nessa direção, o projeto Saberes Wajãpi: formação de pesquisadores e valorização de registros etnográficos indígenas, coordenado por Dominique Gallois (GALLOIS; SZMRECSANYI; WAJÃPI, 2013) ou as "viagens de assessoria", desenvolvidas pela CPI/ AC (WEBER, 2006). 
de colaboração intercultural, envolvendo uma complexa rede de interação com interlocutores diversos. Com as orientações das políticas públicas, os cursos de formação de professores indígenas vêm estimulando movimentos locais de valorização das formas de expressão cultural indígena e da diferença cultural e de produção de materiais didáticos próprios. As formulações dos(as) professores(as) da aldeia Muã Mimatxi a respeito de tais processos, construídas em diálogos estabelecidos com suas redes de interlocução, num movimento contínuo de ressignificação, revelam muitas vezes novas tensões e contradições.

\section{A escola indígena e o movimento em direção à "cultura"}

Quando visitamos a aldeia Muã Mimaxti, em maio de 2012, os professores ressaltaram que o trabalho que realizam na escola é de uma educação diferenciada, e que nesse longo processo de formação e de diálogo com os não índios, a comunidade vem buscando encontrar o seu caminho em sintonia com os seus projetos de vida.

Quando não tinha a educação escolar indígena, nossas crianças aprendiam sem ter prédio, sem ter essa coisa, mas hoje nós temos que lutar pra isso porque é um direito que a gente tem que tem que ter. E também teve mais um pouco de respeito, porque antes, quando começou, logo as pessoas falavam que, às vezes, tinham um pouco de receio das escolas indígenas. Falavam assim "será que estão ensinando certo?" O que é ensinar certo, então? Às vezes, as pessoas pensam que estão ensinando certo, não, isso não está certo. Então, cada um tem o seu jeito de educar o seu povo, sua criança. Talvez o que é certo pra uma escola que não é indígena, pra nós, não é certo. Pra nós não é certo. Às vezes, não é certo estudar o tempo todo dentro de uma sala de aula, pra nós não é certo, às vezes, é certo ter um livro, pagar livro, comprar livro. Pra nós, talvez, se a gente for fazer uma caminhada, for trabalhar com atividade da vida social ou recreativa ou com brincadeira, a gente pode estar aprendendo ali, tirando um instrumento da vida daquelas atividades da vida. E isso nãoéerrado, mas para a Secretaria isso não vale muito, mas pra nós vale. Então, a gente tem que saber fazer esse manejo, esse manejo de educação. E também é uma coisa que nós não temos medo de enfrentar, porque nós estamos vendo que é certo (Kanatyo).

Como vocês viram hoje, a nossa educação, a nossa escola. [...] A gente sempre luta para ampliar a nossa escola, mas a nossa aula não é só dentro 
da sala, não é só dentro da sala fechada ali, às vezes, a gente está ali fora trabalhando, muitas vezes, a gente está lá no terreiro, lá embaixo, trabalhando. Às vezes, passa uma pessoa e diz assim: "É hora de aula e vocês estão aí." Mas é um conhecimento que outras pessoas lá de fora não estão conseguindo ver. A gente está passando aquilo para os nossos alunos (Duteran).

Como se vê nesses falas, há uma tentativa de ajustar as práticas pedagógicas desenvolvidas em uma instituição que historicamente representou uma ameaça ao modo de vida dos antigos para se tornar hoje um lugar que pode apoiar as comunidades indígenas no seu projeto de promover um diálogo diferenciado com os saberes tradicionais.

Nessa perspectiva, Kanatyo ressalta que a escola indígena se apresenta hoje como "a orientadora da comunidade", na medida em que está voltada para dois eixos centrais do projeto de vida da aldeia - a memória e a sustentabilidade das novas gerações -, que articulados envolvem um diálogo entre o passado e o futuro, entre os mais velhos e os mais jovens, com a mediação e a liderança dos(as) professores(as).

Como "núcleo da memória", a escola da aldeia envolve os alunos em atividades que estimulam o diálogo com os saberes tradicionais do povo Pataxó, de uma forma dinâmica, que permite torná-la "uma escola viva, alegre, que a gente sente desejo de estar presente todo dia, porque ela é nossa vida [...]". Kanatyo cita como exemplo sua própria experiência na alfabelização das crianças, mostrando como, por meio da música, consegue despertar o interesse pela cultura tradicional Pataxó, produzir conhecimentos e valorizar os saberes e as experiências das pessoas da comunidade.

[...] muita escola tem dificuldade em alfabetizar, e eu tenho a maior facilidade de alfabetizar criança, pegar criança assim novinha com seis anos, pego ela em fevereiro quando é em abril ela já tá lendo tudo. [...] A música é uma questão muito interessante, porque ela serve pra alfabetizar. Eu mesmo, com música dou aula para qualquer pessoa. Não é só de alfabetização não, qualquer pessoa, se eu cantar uma música minha, uma música que eu mesmo componho, eu dou aula. Eu trabalho com geografia, história, filosofia, antropologia, um monte de coisa que eu trabalho dentro da música, que é uma coisa gostosa. Então, qual professor que faz isso? É difícil, é raro a gente ver isso, e a nossa escola tem essa facilidade da gente tentar passar isso para as crianças, fazer eles produzirem o seu próprio material. Serve como uma experiência pra se expandir também, porque nós não queremos que nossa educação seja uma coisa fechada, nós não 
queremos, mas queremos vender nossa produção pra reconhecer também. Então, nossa escola ela trabalha com essas questões aí.

Na fala de Kanatyo, esse eixo da memória se encontra articulado com o tema da "cultura", entendida como "artesanato, festas, brincadeiras, jogos", que "são coisas interessantes que podem servir como fonte de conhecimento" e despertar os jovens para a questão da cultura. Por sua vez, memória e cultura se encontram relacionadas ao eixo da sustentabilidade, na medida em que o trabalho desenvolvido com os alunos, a exemplo dos jogos produzidos na pesquisa do Siuê para o $\mathrm{FIEI}^{6}$, contempla a produção de materiais didático-pedagógicos.

[...] através da cultura a gente pode desenvolver muita coisa que possa segurar nós na terra. Aqui já nasceram umas doze crianças, já são filhos da terra, então a gente tem que [...] garantir a vidas dessas crianças. [...] A escola tem que pensar nisso, e a gente ta pensando muito nessa coisa da cultura, porque a cultura é uma coisa que pode segurar nós na terra. [...]. O que ela pode produzir? Pode produzir muita coisa em toda comunidade. Porque é através dela que nós vamos tentar trabalhar pra segurar o jovem aqui dentro (Kanatyo).

Segundo Kanatyo, esse tipo de produção cultural, como "livro artesanal", jogos, "livraria viajante", além de transformar o jovem em "autor da sua própria historia, da sua própria vida, da sua própria cultura", pode gerar renda para a comunidade. Ele acredita que a escola tem papel fundamental no desenvolvimento de projetos como esses, estimulando a participação dos alunos no desenvolvimento dessas atividades.

Esse tipo de mobilização em torno de problemáticas relacionadas à "cultura" por parte de professores indígenas, segundo Gallois, Szmrecsanyi e Wajãpi (2013), resulta da constatação do impacto negativo de ações assistenciais praticadas na perspectiva da integração e do apagamento das diferenças. Segundo esses autores, este processo teve início no final da década de 90, quando a ideia de "cultura" (uma noção exógena) foi apropriada para reforçar o fortalecimento político das diferenciações étnicas. Nos últimos anos, esse processo vem ganhando cada vez maior relevância diante das ameaças de abandono pelas

6 Trata-se de um embornal de jogos, material produzido por Siuê como resultado final da pesquisa desenvolvida no Percurso Acadêmico do FIEI e apresentado como trabalho de conclusão de curso, questão que será aprofundada em outra oportunidade. 
gerações mais jovens dos valores e saberes dos mais velhos.

Weber (2006) descreve como, no início da década de 90, começaram a ser introduzidas ideias como revitalização da cultura e resgate dos mitos em cursos oferecidos pela CPI/ AC, em um movimento de valorização da "cultura" que somente se firmou entre os professores Kaxinawá7 na década seguinte. A partir dos anos 2000, a escola, antes vista e valorizada como espaço de aprendizagem do mundo do branco, tornou-se o centro do movimento pró-cultura e de efervescência cultural, lugar de incremento da vida coletiva, dos encontros, reuniões, festas e também das brincadeiras, cantos e histórias tradicionais.

Desde os anos 2000, segundo essa autora, o termo "cultura" tem se popularizado entre os Kaxinawá, assumindo os mais diversos significados, apreendida por eles em uma perspectiva que não é nem a dos brancos, nem a dos índios, mas que, entretanto, vem produzindo efeitos importantes. Entre eles, o de abrir um novo espaço na vida cotidiana das aldeias para as brincadeiras tradicionais, as sessões e cantos do cipó, para revigorar o interesse pelo artesanato em tecido, para a aprendizagem da língua nativa, entre tantos outros efeitos positivos.

Esse movimento começou com a participação em cursos oferecidos pelas organizações indígenas às lideranças, professores e agentes de saúde, que então foram percebendo que estavam "jogando (a cultura) na mata e dando valor no que não é nosso" (WEBER, 2006, p. 152). Os informantes da autora foram vendo que era importante conhecer o mundo dos brancos, mas que conhecer o mundo deles era até mesmo mais importante e, aos poucos, foram convencendo os pais dos alunos; assim o movimento de "resgate da cultura" foi se expandindo e se fortalecendo nessas aldeias Kaxinawá.

Weber (2006) ressalta que esse interesse atual pela "cultura" entre os Kaxinawá demonstra o empenho em se ajustarem a uma demanda externa, e que isso é interpretado por eles como outra forma de estar unindo o branco com o índio. A autora ressalta a importância de análises que atentem para as repercussões desse discurso de valorização da "cultura" na vida cotidiana dos povos indígenas. No caso dos Kaxinawá por ela estudados,

7 Pesquisa realizada entre os Kaxinawá da Terra Indígena Rio Humaitá, no Acre. 
a cultura que vinha sendo "jogada na mata", "jogada para o lado", estava agora sendo trazida de volta e provocando mudanças consideráveis no seu cotidiano de vida. Entre tais mudanças, menciona a presença dos mitos no dia a dia; a referência constante das crianças a histórias do universo mítico; os cantos rituais ensinados na escola eram aprendidos pelas crianças com entusiasmo, tornando as aulas alegres e contagiantes; as brincadeiras da cultura, apesar de recortadas e folclorizadas, são incorporadas como parte de sua diferença como índios Kaxinawá, remetendo a um passado que por muitos anos foi motivo de vergonha.

Como se pode ver, a cultura (a sem aspas), como um processo vivo, que faz parte da vida das pessoas em sua experiência cotidiana, está sempre se reinventando. Não é um dado ou um somatório de sinais diacríticos, mas o que está subjacente a eles. E a escola, nessa perspectiva, tornou-se parte importante desse processo, deixando de ser "uma coisa de fora", como ressaltou Kanatyo. Como em muitos outros contextos do país, também na aldeia Muã Mimatxi, tornou-se uma instituição que serve à comunidade e aos seus ideais de vida coletiva. Além disso, como um espaço intercultural por excelência, tornou-se também um lugar para aprofundar o diálogo com o mundo dos brancos e, no caso dos Pataxó dessa aldeia, para alimentar o seu desejo constante de ampliar suas redes de relações e trocas. Isso inclui a aquisição de ferramentas importantes do mundo dos brancos, tais como conhecimentos que poderão lhes abrir, entre outras coisas, oportunidades de trabalho remunerado e os conhecimentos da sua "cultura", cada vez mais valorizados nas redes de trocas com a sociedade envolvente.

Apesar desses aspectos positivos do atual movimento de valorização da "cultura" impulsionado pela escola diferenciada, Gallois, Szmrecsanyi e Wajãpi (2013) apontam também o risco de se entender a cultura como manifestações mais visíveis e palpáveis da própria cultura, associada a lista de objetos, festas, histórias etc. Outro risco, apontado por esses autores, é o apagamento das variações nas manifestações dos conhecimentos tradicionais por diferentes indivíduos ou grupos, na tentativa de encontrar um padrão único, geral e considerado mais verdadeiro. Há dessa forma o risco de apagamento do caráter dinâmico e 
múltiplo da cultura, questão que parece se colocar mais para os assessores brancos do que para os próprios índios, que encontram formas sempre renovadas de domesticação e incorporação da alteridade, como temos visto fazerem em relação à escola.

Acerca desse risco de reificação da cultura, Cunha (2009) há muitojá vem alertando sobre a necessidade de apreender os processos ou procedimentos de produção cultural e não os seus produtos e resultados. Nessa mesma direção, Gallois, Szmrecsanyi e Wajãpi (2013) também enfatizam a importância da colaboração e assessoria antropológica nos processos de formação de pesquisadores no sentido de desvelar a diversidade de lógicas subjacentes às dinâmicas de produção de conhecimento e da cultura. Isso ganha cada vez maior relevância como contraponto aos discursos veiculados pelos órgãos e agentes governamentais, entre eles os da educação indígena, que os incitam a se diferenciar por meio de traços específicos e para a construção de coletivos "genéricos diferenciados" que pressupõem um aglomerado étnico supostamente indiferenciado internamente. Abrir espaço para os diferentes "jeitos" de produzir a diferença cultural, na perspectiva desses autores, torna-se um grande desafio, porém com resultados muito mais promissores do que relacionar a cultura como posse de determinados conteúdos.

Nessa mesma perspectiva, Grupioni (2013) critica o modo "equivocado" como alguns programas de formação de professores indígenas vêm concebendo os conhecimentos e as culturas indígenas, alertando para a influência disso que ele chama de "'cultura' escolar indígena", inclusive, nas formas tradicionais de conhecer.

O que se percebe, em muitos materiais didáticos publicados sob a chancela do diferenciado, é uma simplificação de fórmulas, estratégias cognitivas, lógicas culturais e formas de organização do conhecimento que pouco contribui para sua continuidade e valorização no ambiente escolar. (GRUPIONI, 2013, p. 75)

Além disso, esse autor também destaca o aspecto de coletivização da cultura, veiculado por esses materiais, que apagam ou ignoram diferenças internas aos grupos étnicos a que pertencem os(as) professores(as) em processo de formação. Outro problema apontado é o pressuposto de que esses professores indígenas seriam depositários do conhecimento 
do grupo, como se esse já estivesse dado e, sendo assim, seria fácil transpô-lo na produção de materiais específicos para a escola indígena. Entretanto, como mostram os trabalhos de Cunha (2009) e Gallois, Szmrecsanyi e Wajãpi (2013), é preciso um grande investimento por parte dos colaboradores e assessores da causa indígena no processo de registro e sistematização dos conhecimentos culturais dos diferentes grupos étnicos. A complexidade desse processo colaborativo e dialógico, seja de formação de pesquisadores indígenas ou de pesquisas que visam o fortalecimento do conhecimento tradicional ${ }^{8}$, demanda um tempo mais alargado do que os exíguos tempos da formação de professores indígenas, como ressaltou Grupioni (2013).

Manuela Carneiro da Cunha, em conferência no Colóquio Davi Kopenawa e a Hutukara: um encontro com a cosmopolítica Yanomami, ocorrido no início de novembro de 2013, na UFMG, alertou para a necessidade de cooperação entre os cientistas acadêmicos e os "conhecedores tradicionais" em programas de pesquisa capazes de estabelecer pontes entre o conhecimento prático e o que se aprende na escola. Como essa pesquisadora tem feito nos últimos anos, alertou para o fato de que "o conhecimento tradicional é fruto de um processo vivo, que está sempre em transformação. Ele depende da população que o gerou, depende dela para continuar se transformando, se aprimorando" (RIBEIRO, 2013, p. 1). Essa concepção do conhecimento tradicional como um processo em constante construção, e não como algo pronto e consolidado, no entanto, não é comum de se encontrar em muitos profissionais acadêmicos e em muitos programas de formação de professores indígenas.

A respeito do episódio conhecido como $O$ fogo de 51, que atingiu os Pataxó de Barra Velha, na Bahia, em 1951, Kohler (2008), na contramão da tendência de apagar a diversidade, apresentou-nos várias versões, sendo que uma delas foi narrada por um velho índio, a pedido de uma professora, e publicada em um caderno para ser utilizada em suas aulas na escola indígena, na cidade de Itamaraju. Esse autor alertou para o risco de versões como essa estarem sendo utilizadas como via de acesso dos jovens à

8 Podemos citar como exemplos os projetos Bases para um programa de pesquisas interculturais e fortalecimento do conhecimento tradicional (ver RIBEIRO, 2013) e o Saberes Wajãpi, coordenado por Dominique Gallois, já mencionado anteriormente. 
história oral, inclusive, porque apresenta uma visão paternalista e moralista dos índios como manipulados e responsáveis pelo ocorrido, orientando-se cada vez mais para o lado dos brancos. Em tal versão, a figura do capitão que reprimiu a rebelião é apresentada com grande autoridade moral, mostrando-se impregnada de representações da sociedade envolvente, que relega aos índios um papel passivo, como se sofressem seu destino em vez de vivê-lo e decidi-lo. Esse é um exemplo de como pode ser problemático esse processo de transformação da matéria cultural em material pedagógico, cujas consequências ainda pouco conhecemos.

É sobre resultados como esses, produzidos pelos discursos da "cultura" (com aspas), difundidos pela instituição escolar em meio indígena, que Grupioni (2013) nos alerta. Os discursos de valorização da "cultura" na educação diferenciada, mas não só ${ }^{9}$, criaram um campo fértil para a apropriação do conceito de cultura por parte de diferentes atores, produzindo novos sentidos práticos e políticos, com efeitos nos discursos indígenas a respeito da própria cultura, como ressaltou esse autor.

Como vimos no exemplo acima mencionado, com discursos de valorização dos conhecimentos dos mais velhos e de produção de materiais didáticos próprios, os(as) professores(as) indígenas podem estar contribuindo para produzir sujeitos sociais muito diferentes daqueles desejados pelo movimento criativo de revitalização cultural empreendido por várias etnias na atualidade.

Essas questões nos levam a pensar na importância de trabalhos colaborativos entre assessores não índios e os índios para apoiar os projetos locais de sistematização de conhecimentos tradicionais, registro de tradições orais e produção de materiais didáticos, desenvolvidos na escola indígena. Como mencionamos, já existem iniciativas nessa direção, mas ainda em número muito insuficiente diante da enorme demanda gerada pela expansão da formação superior de professores indígenas. $\mathrm{O}$ movimento de valorização da "cultura", desencadeado pela construção da educação diferenciada, está a exigir um processo continuado e mais sistemático de formação de professores e de pesquisadores indígenas,

9 Isso acontece em vários campos e não apenas na educação indígena, estimulado pelas políticas públicas de valorização da diversidade cultural. 
que conte com a colaboração de equipes interculturais e interdisciplinares e com a participação fundamental de antropólogos. Grupioni (2013) chamou a atenção para a importância do diálogo entre a antropologia e a educação no campo da formação de professores indígenas, especialmente por suas reflexões a respeito da noção de cultura.

Na aldeia Muã Mimatxi, o movimento de revitalização da "cultura" parece estar abrindo ricas possibilidades e não apenas para a aldeia. Os jogos produzidos por Siuê como material didático, por exemplo, aponta também um campo fértil para a ampliação do diálogo da educação indígena com universidades e escolas, por exemplo, disponibilizando esse tipo de materiais também para a formação de crianças, jovens e professores não índios.

O outro eixo da sustentabilidade que Kanatyo deseja ver incorporado à escola indígena são os projetos relacionados à terra. Ele acredita que a escola poderia engajar mais os alunos em atividades como "plantar muda, fazer horta", "alguma coisa assim que tem relação com a vida das crianças e com as famílias" e, assim, servir melhor à comunidade. Segundo ele, se a escola incentivar o trabalho dos alunos com a terra, com o plantio, com a capina da roça, e fizer isso de uma maneira organizada, poderia gerar aprendizagens importantes e muitos conhecimentos sobre a terra, sobre a natureza e sobre a sua importância na vida coletiva.

Tais questões nos remetem novamente para as pesquisas colaborativas e formação de agentes comunitários, propostas por redes de pesquisadores acadêmicos, organizações não governamentais e associações indígenas, que ajudem as comunidades indígenas no reconhecimento e sistematização de práticas tradicionais de conviver com o território e na formulação de novas perspectivas para outros modos de viver ${ }^{10}$. Equipes multidisplinares de assessoria a comunidades indígenas, dessa forma, podem contribuir para a busca de autonomia econômica e de alternativas sustentáveis em terras indígenas ${ }^{11}$. Nessa direção, podemos destacar também o estímulo à participação de agentes agrofloretais e de saúde no âmbito escolar,

10 ISA. A importância da gestão territorial para a autonomia e sustentabilidade das Terras Indígenas. Facebook, 24 nov. 2013.

11 Ver, como exemplo, o projeto piloto, desenvolvido em Roraima: Makuchana: em busca da autonomia e sustentabilidade das terras indígenas do Taiano. (GOMES; KLEIN e SANTOS (2013) 
como parte das ações de assessoria às comunidades indígenas, como proposto pela CPI/ AC. Como ressaltou Weber (2006), isso pode ampliar as oportunidades de socialização de conhecimentos transmitidos nos cursos e oficinas de formação, reforçando a escola como espaço de transmissão de conhecimentos práticos e ligados à vida cotidiana.

Atribuir à escola diferenciada um papel de contribuir para a elaboração de alternativas locais de uso do território e de sustento para as novas gerações, como propõe Kanatyo, coloca-se como mais um desafio para que a escola se adapte à realidade dessas comunidades. Exige a continuidade dos projetos e pesquisas iniciados nos cursos de formação de professores, por meio de assessoria às aldeias, e a elaboração conjunta, conforme as demandas das comunidades, de cursos, oficinas e outros projetos colaborativos, considerando-se uma perspectiva temporal muito mais ampla do que aquelas oferecidas na formação inicial.

Na concepção de Kanatyo, a escola "tem que ser ... fazer parte da nossa vida", por isso, "a gente pode fazer artesanato na escola", no entanto, "o povo da Secretária não aceita isso, mas eles têm que aceitar". Como se pode ver nessa fala, o rumo que os(as) professores(as) da aldeia desejam para a sua escola, muitas vezes entra em tensão com as normas da Secretaria de Estado da Educação, que é quem contrata os(as) professores(as) e fiscaliza as escolas indígenas.

\section{Escola própria, diferenciada ou intercultural?}

Desde que o Ministério da Educação (MEC) passou a coordenar a educação indígena, em $1991^{12}$, incentivou a criação de instâncias gestoras nas Secretarias Estaduais de Educação para cuidar das escolas e da formação dos professores indígenas, especialmente a instituição e regulamentação do Magistério Indígena. Com a Resolução n. 3/99, o Conselho Nacional de Educação definiu as esferas de competência entre

\footnotetext{
12 O Decreto n. 26/91, da Presidência da República, transferiu a responsabilidade e a coordenação das iniciativas educacionais em terras indígenas da Fundação Nacional do Índio (Funai) para o Ministério da Educação (MEC), em parceria com as Secretarias Estaduais de Educação. Segundo Grupioni (2006), com essa determinação, as escolas indígenas foram incorporadas aos sistemas de ensino do país, colocando fim ao ciclo de atendimento das necessidades educacionais indígenas por missões religiosas.
} 
União, Estados e Municípios em relação ao funcionamento das escolas indígenas. Coube aos Estados, que podem contar com a colaboração dos municípios, a oferta e a execução da educação escolar indígena. A resolução estabelece como responsabilidade da União a elaboração de diretrizes e políticas nacionais, assim como apoio técnico e financeiro para o provimento dos programas (GRUPIONI, 2006).

Em todos esses anos de construção conjunta de uma escola diferenciada, específica, bilíngue e intercultural, muitos avanços ocorreram, mas as comunidades indígenas ainda têm muito que lutar para assegurar esse direito constitucional, como nos aponta Kanatyo:

Coube mais um pouco de respeito, mas a gente ainda encontra dificuldade, porque não tem ainda uma política que realmente possa ter tudo certinho sobre as escolas indígenas. Ainda não tem um programa certo pra poder desenvolver. Temos que preencher certa documentação do branco, essas coisas todas dessas escolas lá de fora, papelada, essas coisas. Tem isso tudo, isso eu acho que tem que fazer uma mudança, mas tem que ver como é que a gente vai trabalhar. Depende de todas as comunidades indígenas, não é só a nossa aqui. Mas enquanto a nossa aqui, a gente vai levando, a gente conversa, mostra, apresenta os trabalhos da gente pra o povo da Secretaria, e estamos tocando o trabalho aí.

Tais questões nos remetem à Tassinari (2001), quando ressalta as dificuldades de operacionalização governamental e administrativa do direito indígena a uma educação diferenciada e de adequação dos sistemas de ensino às tradições indígenas. Segundo a autora, isso ajuda a pensar a escola indígena como um espaço de fronteira, que não se configura como uma instituição externa e opressora, mas também não consegue se ajustar completamente aos desejos e expectativas das comunidades indígenas. Como espaço de fronteira, "nem tudo se encaixa" e "nem todos se entendem", apesar dos esforços empreendidos pelos professores indígenas e pelos agentes da etnoeducação ou do sistema educacional.

Nessa perspectiva da autora, há conhecimentos advindos da escola que se articulam bem com as expectativas e visões de mundo indígenas, mas há também certos conhecimentos indígenas que não são facilmente incorporados ao currículo escolar. Tassinari (2001) menciona algumas zonas de desencontros e desentendimentos, entre elas, a legislação e a burocracia estatal que limitam a autonomia e impossibilitam a construção 
de escolas indígenas consoantes com o desejo das comunidades. Da mesma forma, podemos mencionar certas características da escola ocidental, como a separação entre as disciplinas, ritmos de aulas, regimes de trabalho dos professores etc. Acerca dos processos constantes de negociação entre a Secretaria da Educação e a comunidade, Siuê comenta:

E a gente vê que as coisas que a Secretaria queria impor sobre nós, hoje a gente não aceita. Então, a ordem é de baixo para cima na escola indígena. Então a gente não aceita coisa que vem da Secretaria direto de lá pra cá. Por exemplo, hoje na coordenação tem eu, que estou nessa linha de frente, mas eu não faço tudo sozinho, sempre a gente discute com os outros professores pra decidir tudo em grupo. Então, essa coisa de estar na frente, ela não é bem estar na frente, é de você estar compartilhando o conhecimento com os outros, você nunca faz uma coisa sozinho dentro de uma escola indígena. Você tem que sempre compartilhar com o outro para você ouvir, para você se reforçar, para você defender o seu direito. Então, isso que é importante (Siuê).

A escola indígena apresenta também muitas possibilidades de trocas, fluxos e intercâmbios de conhecimentos e de pessoas, e as próprias zonas de tensão acabam fornecendo materiais para reforçar diferenças ou manter distinções étnicas, como reconhece Tassinari (2001). Dessa forma, oferece um terreno criativo e fértil que permite repensar conhecimentos e tradições, tanto para os índios, como para os não índios. Apesar das tensões mencionadas acima, e entre o que acontece no papel e o que acontece na prática, parece predominar as orientações ditadas pela própria comunidade, conforme mostra esta fala de Kanatyo: “aqui nós fazemos do nosso jeito", pois a preocupação central é com a "vida do nosso jovem, da nossa criança, esse é o maior pensamento que nós temos".

Em visita à escola da aldeia, em maio de 2012, encontramos todos os alunos e professores envolvidos na elaboração coletiva de uma atividade relacionada ao Tempo das Águas Claras, um ciclo do Calendário Socioecológico. Esse instrumento teórico-metodológico desenvolvido por María Bertely Busquets e Jorge Gasché, experimentado na formação de professores indígenas em países como o Perú e o México ${ }^{13}$, foi-lhes apresentado em uma das disciplinas do FIEI e, após a conclusão do curso, continuou sendo desenvolvido como projeto na escola da aldeia. Essa

13 Acerca do Calendário Socioecológico, ver: Gasché (2013), Silva (2012) e Pádua e Veas (2013). 
ideia do Calendário Socioecológico, nascida da interlocução com professores do FIEI-UFMG, engajou os alunos da escola na tarefa de desenhar em cartolinas as histórias e os mitos tradicionais Pataxó que ouviram dos mais velhos da comunidade sobre o tempo mítico dos seus ancestrais, em aulas chamadas de interculturais. As carteiras foram levadas para o lado de fora, no pátio da escola e estavam todos concentrados na tarefa e não havia nenhum professor dando explicações, esses acompanhavam a atividade, às vezes ajudando, às vezes apenas observando. No dia seguinte, como ainda não tinham terminado a tarefa, os alunos seguiram realizando a mesma atividade com as carteiras novamente dispostas no pátio da escola, em grande silêncio e concentração. Quando terminaram, foram todos para a sala de aula para socializar entre si e com os professores as histórias que desenharam e recriaram.

Como se pode ver, os(as) professores(as) da aldeia Muã Mimatxi parecem estar conseguindo construir uma escola própria, que segue os interesses e ritmos da vida comunitária. No entanto, se considerarmos que as redes de interlocução construídas nos cursos de formação, a escola da aldeia é também o resultado de múltiplas influências formadoras "emaranhadas por um pensamento próprio", como nas palavras de Rappaport e Pacho (2005, p. 40). Com o instrumento do Calendário Socioecológico ${ }^{14}$, essa rede de interlocução se ampliou ainda mais, abrindo novas trilhas até o Peru e o México.

Construída nesse contexto de diálogo e colaboração, a escola indígena é fundamentalmente intercultural. Quando analisada a partir de dentro e na perspectiva deles, ela é um híbrido criativo de transformações, cujas influências "estrangeiras" são sempre digeridas e deslocadas para assumir funções que os próprios índios lhe atribuem, como sugeriu Franchetto (2010).

No entanto, como um processo continuamente negociado com outros atores e especialmente com a Secretaria de Estado da Educação, pode ainda ser pensada como espaço de fronteira, por comportar, ao mesmo tempo, muitas possibilidades, mas também muitas tensões e contradições.

Nessa perspectiva, acerca dos embates com a Secretaria de Educação,

14 Dada a sua relevância na pesquisa, esse tema será aprofundado em outra oportunidade. 
Grupioni (2006) ressalta que mesmo com a falta de qualificação dos agentes educacionais e os rígidos esquemas administrativos, os avanços na legislação abriram um horizonte bastante promissor e desencadearam um rico e intenso processo de educação escolar indígena em todo o país. No entanto, os(as) professores(as) Duteran e Sarah, mesmo ressaltando os aspectos positivos alcançados pela educação diferenciada praticada na aldeia, remetem-nos a outro ponto de tensão: a ida de jovens estudantes para as cidades em busca de continuidade da escolarização.

Em maio de 2012, três jovens da aldeia cursavam o Ensino Médio na cidade e esses(as) professores(as) da aldeia ressaltaram com orgulho o bom desempenho alcançado por eles, como resultado do trabalho desenvolvido na escola indígena.

O pessoal elogia muito eles, fala que eles são uns meninos muito inteligentes, e que têm muita facilidade. Então, a gente vê assim que a interculturalidade está aí também na facilidade da pessoa conseguir entender o que vai vir pra ele lá fora. Lá fora é só coisas picadas, cada matéria tem seu horário. [...] Então, a gente vê assim que nosso jeito de ensinar não está sendo um jeito fraco (Duteran).

[...] Os professores estão elogiando os meninos daqui, falam que são os melhores alunos que vão pra escola. Os alunos que tiram notas boas, os alunos que não dão trabalho. [...] Então eu acho assim que é muito bom, é muito bom pra nossa escolinha, que muita gente não acreditou (Sarah).

E quando hoje vejo os alunos lá do Ensino Médio e os que já formaram lá, a gente vê que eles saíram daqui, desde lá, quando a gente começou em 96 e já se formaram, formaram aqui. Eu acho que isso é bom demais porque no início eles não acreditaram na escola indígena (Sarah).

Como se pode ver, como ressaltou Tassinari (2001), a escola borra as fronteiras mesmo quando empurra os jovens para a cidade, pois esses podem retornar às aldeias dispostos a investir nos projetos comunitários de valorização da cultura. Para o alcance desses resultados, como os próprios professores(as) ressaltaram, foi fundamental a experiência de trabalho coletivo e intercultural que teve início em 1996, com a sua participação no curso de Magistério Indígena e que continuou no FIEI, curso superior que concluíram em 2011:

Então, através das apostilas, através dos DVDs, do conhecimento dos outros professores de lá que não são índios, então, a gente veio trazendo 
também. Então, se a gente não tivesse feito esse curso, como que a gente ia passar esses conhecimentos para os alunos? Vamos supor, ia ter que estar pesquisando. Lá não, a gente já trouxe esse conhecimento de lá para cá, pra passar pra eles, então, não foi em vão. (Sarah)

Nessa perspectiva, Sarah afirma que o trabalho desenvolvido hoje pelos professores na escola indígena da aldeia Muã Mimatxi "mudou foi pra melhor", "assim de estar passando para os alunos o que eu aprendi lá, o que foi bom".

\section{Considerações finais}

Essa maneira de pensar a escola e a formação dos(as) professores(as) Pataxó parece indicar a presença entre eles de um ethos comum a muitas sociedades ameríndias, que atribui centralidade às trocas e relações com outros, não para se tornar como eles, mas para fabricar permanentemente novas experiências e significações. Nessa filosofia de socialidade (VIEGAS, 2002), os encontros com a alteridade ajudam a produzir uma história em permanente processo de transformação, que entrelaça o devir e ressignifica a memória.

Nesse sentido, as experiências vividas no FIEI, apreendidas por tal filosofia, transformaram a escola em centro da vida comunitária, apropriada para exercitar uma concepção de conhecimento como projeto e como pesquisa que os ajuda a repensar a sua relação com o mundo e a produzir seus projetos de futuro. O Calendário Socioecológico, uma ideia nascida desses encontros com a alteridade durante o processo de formação intercultural, ganhou relevância na medida em que permitiu exercitar a pesquisa permanente e ligada à prática social para produzir novos conhecimentos e realidades, em sintonia com as concepções de mundo desse povo indígena. 


\section{Referências}

CUNHA, Manuela Carneiro da. "Cultura" e cultura: conhecimentos tradicionais e direitos intelectuais. In: CUNHA, Manuela Carneiro da. Cultura com aspas e outros ensaios. São Paulo: Cosac Naify, 2009. p. 311-373.

FRANCHETTO, Bruna. Micol Brazzabeni, La Scuola di Carta: una ricerca di antropologia dela formazione tragli insegnanti tikmu'un del minas gerais. Etnográfica, v. 14, n. 2, p. 2-6, 2010.

GALLOIS, Dominique Tilkin; SZMRECSANYI, Lúcia; WAJÃPI, Pesquisadores. Saberes Wajãpi: formação de pesquisadores e valorização de registros etnográficos indígenas. In: STEPHEN, L.; HALE, C. R. (Org.). Outros saberes. Collaborative research on indigenous and afro-descendent cultural politics. Santa Fé: School of American Research Press, v. 1, p. 49-74, 2013.

GASCHÉ, Jorge Suess. Éxitos y fracasos de una propuesta educativa basada sobre el "Método Inductivo Intercultural" e implementada en el Perú, México y el Brasil. ISEES, n. 13, p. 17-31, jul./dez. 2013. Disponível em: <http://www.isees.org/file.aspx?id=7620>. Acesso em: 17 outubro 2013.

GOMES, Selma; KLEIN, Tatiane e SANTOS, Tiago Moreira dos (Eds.). Makuchana: em busca da autonomia e sustentabilidade das terras indígenas do Taiano. São Paulo: Instituto Socioambiental, 2013. Disponível em: http:/ / www.socioambiental.org/pt-br/o-isa/ publicacoes/makuchana-em-busca-da-autonomia-e-sustentabilidadedas-terras-indigenas-do-taiano.

GRUPIONI, Luís Donisete Benzi. Políticas indigenistas. Povos Indígenas no Brasil. ISA, maio 2006. Disponível em: <http:/ / pib. socioambiental.org/pt/c/politicas-indigenistas/educacao-escolarindigena>. Acesso em: 23 fev. 2008.

GRUPIONI, Luís Donisete Benzi. Quando a Antropologia se defronta com a Educação: formação de professores índios no Brasil. Pro- 
Posições, v. 24, n. 2, p. 69-80, maio/ago. 2013. Disponível em: <http:/ / www.scielo.br/pdf/pp/v24n2/v24n2a06.pdf>. Acesso em: 20 novembro 2013.

ISA. A importância da gestão territorial para a autonomia e sustentabilidade das Terras Indígenas. Facebook, 24 nov. 2013.

LASMAR, Cristiane. Conhecer para transformar: os índios do rio Uaupés (Alto Rio Negro) e a educação escolar. Tellus, Campo Grande, ano 9, n. 16, p. 11-33, jan./jun. 2009.

KOHLER, Florent. Um cordel indígena: história dos dois ladrões que obrigou os índios robar. HAL Archive ouverte pluridisciplinaire, v. 1, 13 mar. 2008. Disponível em: <http:/ / halshs.archivesouvertes.fr/ docs/00/26/36/89/PDF/Cordel_Florent_Kohler.pd>. Acesso em: 10 outubro 2013.

PÁDUA, Karla Cunha. "Pegando as frutinhas que estão melhor para comer": afirmação de diferenças e transformações culturais em contextos de formação de educadores indígenas. 296 f. 2009. Tese (Doutorado em Educação) - Faculdade de Educação, Universidade Federal de Minas Gerais, Belo Horizonte, 2009.

PÁDUA, Karla Cunha; VEAS, Maria Regina Lins Brandão. Recorrido Académico e interculturalidad en la formación de educadores indígenas. ISEES, n. 13, p. 35-50, jul./ dez. 2013. Disponível em: <http:/ / www.isees.org/file.aspx?id=7620>. Acesso em: 20 outubro 2013.

RAPPAPORT, Joanne; PACHO, Abelardo Ramos. Una historia colaborativa: retos para el diálogo indígena-académico. Historia Crítica, n. 29, p. 39-62, jan./jun. 2005.

REZENDE, Luisa Andrade Lobo de. When a university opens itself to diversity: a brief report on the Intercultural Formation Course for Indigenous Teachers, from the Federal University of Minas Gerais (UFMG), Brazil. Intercultural Education, v. 20, n. 3, p. 203-210, 2009. Disponível em: <http://dx.doi.org/10.1080/14675980903138483>. 
Acesso em: 8 out. 2013.

RIBEIRO, Ewerton Martins. É um erro escolarizar o conhecimento tradicional, avalia pesquisadora da USP. Notícias da UFMG, 21 nov. 2013. Disponível em: <https://www.ufmg.br/online/ arquivos/031025.shtml>. Acesso em: 12 janeiro 2014.

SAHLINS, Marshall. O "pessimismo sentimental" e a experiência etnográfica: por que a cultura não é um "objeto" em via de extinção (Parte I). Mana, v. 3, n. 1, p. 41-73, 1997a.

SAHLINS, Marshall. O "pessimismo sentimental" e a experiência etnográfica: por que a cultura não é um "objeto" em via de extinção (Parte II). Mana, v. 3, n. 2, p. 103-150, 1997b.

SILVA, L. J.. El método inductivo intercultural y el Calendario Socioecológico como estrategias para el fortalecimiento de una formación crítica e intercultural de professores indígenas de los estados de Minas Gerais y Bahia, Brasil. ISEES, v. 10, p. 79-94, jan./ jun. 2012.

TASSINARI, Antonella Maria Imperatriz. Escola Indígena: novos horizontes teóricos, novas fronteiras de educação. In: SILVA, Aracy Lopes da Silva; FERREIRA, Mariana Kawall Leal (Orgs.). Antropologia, História e Educação: a questão indígena e a escola. São Paulo: Global, 2001. p. 44-70.

VIEGAS, Susana de Matos. Trilhas: território e identidade entre os índios do sul da Bahia/Brasil. In: RAMALHO, M. I. E RIBEIRO, A. S. (Orgs.). Entre ser e estar: raízes, percursos e discursos da identidade, v. 8, parte 1. Porto: Afrontamento, 2002. p. 185-211.

WEBER, Ingrid. Um copo de cultura: os Huni Kuin (Kaxinawá) do Rio Humaitá e a escola. Rio Branco: EDUFAC, 2006.

Recebido em19/03/2014 Aprovado em 07/06/2014 